All letters are subject to editing and may be shortened. General letters can be sent to bjgpdisciarcgp.org.uk (please include your postal address for publication), and letters responding directly to BJGParticles can be submitted online via eLetters. We regret we cannot notify authors regarding publication.

For submission instructions visit: bjgp.org/letters

\section{MUS: actually we can and should explain such symptoms}

The authors of this article make frequent reference to 'unexplained' and even 'unexplainable' symptoms.' However, the work of Professor Christopher Burton, among others, has clearly identified helpful explanations for such functional symptoms. Using more positive language about normal ageing (wear and repair), the effects of chronic muscle tension and weakness (back pain, deconditioningl, the effects of vicious cycles of focusing on symptoms and ignoring pain-free periods (by both doctors and patients), and the effects of the adrenocorticoid system are some of the helpful ways to talk about functional symptoms. ${ }^{2-4}$ Dobbin has highlighted the need for doctors to understand the mindbody relationship and the healing potential for positive social and other feedback via parasympathetic networks. ${ }^{5}$

We can recognise the predisposing factors arising from the effects of trauma and attachment processes in infancy and early childhood, which influence how distress of all kinds is communicated to doctors. ${ }^{6}$ Van der Kolk has elucidated the neurological correlates of abnormal responses to distress; beginning in childhood, stress chronically affects the cortisol axis and affects the brain's responses. ' When we manage distress and insecure attachment skilfully, avoiding unhelpful labels and treating symptoms, we enable better emotional regulation. Mindfulness, 'HeartMath', and bodywork therapies such as yoga are also helpful.

Such patients need long-term supportive relationships with clinicians whose consultation skills enable therapeutic conversations. Doctors should be liberated from the idea that if the tests are normal there must be something wrong that another test will find' or that symptoms are 'unexplained' if there is no structural change. As up to $50 \%$ of the patients may have functional syndromes, every clinician should have excellent explaining skills for these phenomena.

Let us abandon the term 'medically unexplained symptoms'. The origins of functional syndromes can be understood, we can explain them, and we can treat them in collaboration with our longsuffering patients.

Avril Danczak,

GP, Medical Educator, Health Education England North West.

E-mail: avril.danczaklabtinternet.com

\section{REFERENCES}

1. Chew-Graham CA, Heyland S, Kingstone T, et al. Medically unexplained symptoms: continuing challenges for primary care. Br J Gen Pract 2017: DOI: https://doi.org/10.3399/bjgp17X689473.

2. Burton $\mathrm{C}$, ed. ABC of medically unexplained symptoms. Chichester: Wiley-Blackwell, 2013

3. Academic Health Science Network. Improving Patient Pathways for Persistent Physical Symptoms. www.ahsn-nenc.org.uk/project/226/ (accessed 4 Apr 2017).

4. Northern Association for Persistent Physical Symptoms. www.myhealthskills.com/groups/2/ show (accessed 4 Apr 2017).

5. Dobbin A. Burnt out or fired up? Helping recovery in distressed patients can increase our own resilience. Br J Gen Pract 2014; DOI: https://doi. org/10.3399/bjgp14X681661

6. Maunder R, Hunter J. Love, fear, and health: how our attachments to others shape health and health care. Toronto, ON: University of Toronto Press, 2015.

7. van der Kolk B. The body keeps the score: mind, brain and body in the transformation of trauma. London: Penguin, 2015.

DOI: https://doi.org/10.3399/bjgp17X690773

\section{Medically unexplained symptoms: continuing challenges for primary}

\section{care}

I wish doctors would finally start to take patients seriously. ${ }^{1}$ Please doctors, listen to what the patient is telling you!

I've been on an odyssey, trying to get recognition for my symptoms. I have had all kinds of diagnoses: migraines, chronic fatigue syndrome, fibromyalgia, a functional movement disorder, conversion disorder etc. The only tests done were an MRI and a standard blood test.

No doctor I spoke to was interested in my explanation for the symptoms: all of the issues started with an adverse reaction to a commonly prescribed medicine. All of the symptoms are clearly stated in the patient information leaflet. There are thousands of other people with the same problem on internet forums and on Facebook. But the medical community prefers to label us as 'crazy' or 'hypochondriac' instead of addressing the actual problem: unsafe medicines on the market.

Laura Mair,

Patient.

E-mail: lauramair_19801yahoo.de

\section{REFERENCE}

1. Chew-Graham CA, Heyland S, Kingstone T, et al. Medically unexplained symptoms: continuing challenges for primary care. Br J Gen Pract 2017 DOI: https://doi.org/10.3399/bjgp17X689473.

DOI: https://doi.org/10.3399/bjgp17X690785

\section{Medically unexplained symptoms}

I am concerned about the use of the term 'MUS'.' As a patient suffering from iatrogenic harm resulting from withdrawal from a benzodiazepine after 40 years' consumption, I am unable to find a doctor willing to acknowledge the true cause of my current state of neurological disability. I therefore am collecting a myriad of spurious diagnoses such as depression and ME/CFS. This only serves to compound my distress. 'MUS' seems to be another potential dumping ground for the many patients harmed due to prescribed drug dependence and withdrawal, thereby diverting attention away from the real problem.

Fiona French,

Retired, Aberdeen

E-mail: fionahfrenchahotmail.com

\section{REFERENCE}

1. Chew-Graham CA, Heyland S, Kingstone T, et al. Medically unexplained symptoms: continuing challenges for primary care. Br J Gen Pract 2017; DOI: https://doi.org/10.3399/bjgp17X689473.

DOI: https://doi.org/10.3399/bjgp17X690797 